\title{
Desenvolvimento de um instrumento brasileiro para avaliação da cultura organizacional
}

\author{
Maria Cristina Ferreira \\ Eveline Maria Leal Assmar \\ Katia Maria Felipe Estol \\ Universidade Gama Filho \\ Maria Cristina da Costa Chagas Helena \\ Centro Universitário Celso Lisboa \\ Maria do Carmo Figueiredo Cisne \\ Universidade Estácio de Sá
}

\begin{abstract}
Resumo
Foi objetivo do presente trabalho desenvolver e analisar as características psicométricas de um instrumento brasileiro destinado a identificar os valores e práticas que configuram a cultura de uma organização. Tomando por base a análise do conteúdo de entrevistas realizadas com diretores ou gerentes de várias empresas, a versão inicial da escala compôs-se de 126 afirmativas em formato Likert, a qual foi respondida por 823 membros de diversas organizações. Análises fatoriais dos eixos principais, com rotação oblíqua, realizadas separadamente no conjunto de itens concernentes aos valores e às práticas organizacionais, revelaram que soluções de quatro e de três fatores, respectivamente, eram as que melhor representavam a estrutura interna das escalas. Os índices de consistência interna desses fatores, calculados através do coeficiente Alfa de Cronbach, variaram entre 0,74 e 0,93 . Concluiu-se que as características psicométricas do instrumento recomendam seu uso em pesquisas brasileiras destinadas a avaliar a cultura organizacional.
\end{abstract}

Palavras-chave: Cultura organizacional, Percepção de valores organizacionais, Percepção de práticas organizacionais.

\begin{abstract}
Development of a Brazilian instrument for evaluation of organizational culture. The present paper aimed to develop and analyze the psychometric characteristics of a Brazilian instrument designed to identify the values and practices that shape the culture of an organization. Based on the content analysis of interviews with directors or managers from various enterprises, the initial version of the scale was composed of 126 affirmatives, Likert format, and was presented to 823 members from different organizations. The principal factor analysis axis with oblique rotation done separately in the total amount of items related to the values and to the organizational practices revealed that a four factor structure and a three factor structure, respectively, were the best representations of the scales. The internal consistency indexes, calculated by Cronbach's Alpha coefficients, ranged between .74 and .93. It was concluded that the psychometric characteristics of the instrument indicate its adoption in Brazilian investigations, as a tool for the evaluation of organizational culture.
\end{abstract}

Key words: Organizational culture, Organizational values perception, Organizational practices perception.

$\mathrm{D}$ e longa tradição na antropologia, o termo cultura foi incorporado à literatura organizacional na década de setenta, por Pettigrew (1979), através de expressões como "cultura corporativa" ou "cultura organizacional" que, desde então, vêm sendo objeto de abordagens teóricas e metodológicas que ora se assemelham ou se complementam, ora se excluem mutuamente, o que faz com que uma certa falta de consenso ou confusão conceitual ainda prevaleça nessa área.
Para Pettigrew (1979), a cultura organizacional consiste em "um sistema de significados pública e coletivamente aceitos por um dado grupo, em um certo período de tempo. Esse sistema de termos, formas, categorias e imagens interpretam para as pessoas as suas próprias situações" (p. 574).

Já para Schein (1992), um dos autores mais citados na literatura especializada, a cultura organizacional deve ser compreendida como 
um padrão de pressuposições básicas compartilhadas, aprendidas por um grupo, na medida em que resolveram seus problemas de adaptação externa e integração interna, e que funcionaram suficientemente bem para serem consideradas como válidas e, portanto, ensinadas aos novos membros como o modo correto de perceber, pensar e sentir em relação a esses problemas (p. 12).

A revisão comparativa das várias conceituações de cultura organizacional permite, contudo, a identificação de algumas pressuposições gerais acerca desse fenômeno que, em certa medida, sublinham pontos de contato entre as várias tendências. Assim é que Hofstede, Neuijen, Ohayv e Sanders (1990) enfatizam que a cultura organizacional relaciona-se com a história e tradição da organização; tem alguma profundidade; é de difícil decifração e explicação, mas deve ser interpretada; é, por natureza, coletiva, compartilhada e ideacional; referencia-se a valores, crenças, conhecimentos e outros aspectos mais profundos e é holística e subjetiva, ao invés de estritamente racional e analítica.

$\mathrm{Na}$ tentativa de ordenar esse campo de conhecimento, Smircich (1983) propôs uma distinção entre duas principais tendências que vêm direcionando seu estudo. A primeira associa-se a uma perspectiva funcionalista, enfocando a cultura como uma variável, isto é, "algo que a organização tem" (p. 347). Considera-se, assim, que as organizações produzem traços culturais mais ou menos distintos que, em conjunto, afetam o comportamento dos empregados e dirigentes e lhes assinala um senso de identidade, o que lhes facilita maior envolvimento com ela, assegura a estabilidade do sistema e serve como um instrumento de orientação e modelagem do comportamento. A segunda tendência, de tradição fenomenológica, aborda a cultura como metáfora de raiz, ou seja, como "algo que a organização é" (p. 347). Nesse sentido, as organizações são concebidas como manifestações que expressam a consciência humana, e, por essa razão, devem ser analisadas através de seus aspectos expressivos, ideacionais e simbólicos que tornam possível a ação compartilhada.

Orientados pela perspectiva funcionalista, diferentes autores têm procurado desenvolver modelos teóricos destinados a explicitar os diferentes traços ou elementos através dos quais a cultura organizacional pode se manifestar. Em se tratando, por exemplo, do modelo teórico de Schein (1991), são propostos três níveis de elementos, que variam em função do seu grau de acessibilidade: os artefatos, os valores esposados e os pressupostos básicos. Os artefatos constituem o nível mais superficial da cultura, isto é, correspondem às estruturas e processos organizacionais e aos produtos tangíveis do grupo, tais como a arquitetura do ambiente físico e as cerimônias observadas. Os valores esposados, por sua vez, justificam as estratégias, metas e filosofias organizacionais, enquanto os pressupostos básicos se referem a crenças que passam a fazer parte da visão de mundo dos membros, e assim, tendem a se tornar inconscientes e inquestionáveis. De acordo com o autor, os pressupostos básicos constituem o cerne da cultura da organização e, por essa razão, seus estudos têm se valido de métodos qualitativos, considerados por ele como os únicos capazes de detectar tais elementos inacessíveis, profundos e inconscientes.

Rousseau (1990) propôs um modelo segundo o qual os principais elementos da cultura apresentam-se dispostos em "camadas", que variam ao longo de um "continuum" de subjetividade e acessibilidade e se inter-relacionam entre si. Partindo-se dos elementos mais visíveis para os mais profundos, observa-se a seguinte ordem: artefatos, padrões de comportamento, normas comportamentais, valores e pressuposições fundamentais. Em um certo sentido, esse modelo representa uma ampliação do de Schein (1991), incorporando um maior grau de especificidade na determinação e distinção entre as várias formas de manifestação da cultura. Desse modo, a autora acrescenta aos elementos culturais definidos por Schein (1991) os padrões de atividades (tais como os mecanismos de tomada de decisão, coordenação e comunicação utilizados na resolução dos problemas organizacionais) e as normas comportamentais (expectativas da organização sobre como seus membros devem se comportar e interagir com os outros, no que se refere, por exemplo, às relações de cooperação ou competição entre colegas).

Em seus estudos sobre cultura organizacional, porém, Rousseau (1990) tem priorizado as normas comportamentais compartilhadas, avaliadas através do Inventário de Cultura Organizacional (OCI), desenvolvido por Cooke e seus colaboradores (Cooke \& Lafferty, 1984, 1989; Cooke \& Rousseau, 1988; Cooke \& Szumal, 1993). O referido instrumento é constituído de doze escalas associadas a doze diferentes estilos culturais que se agrupam em três dimensões ou tipos gerais de cultura, quais sejam: cultura construtiva (estilos humanístico-encorajador, afiliativo, de realização e de autoexpressão); cultura passivo-defensiva (estilos convencional, de aprovação, de dependência e de evitação) e cultura agressivo-defensiva (estilos de oposição, de poder, competitivo e perfeccionista). A análise das características psicométricas do instrumento evidenciou que a consistência interna das escalas variou de 0,67 a 0,95 e que os resultados obtidos na análise fatorial deram suporte à sua validade de construto.

O modelo teórico concebido por Hofstede e colaboradores (1990) pressupõe que a cultura se manifesta através de quatro elementos, que também diferem em termos de sua visibilidade para o observador. Os símbolos, a camada mais externa, compreendem as palavras, gestos e objetos que têm significado especial dentro da organização. Os heróis são as personagens vivas ou mortas, reais ou imaginárias, revestidas de prestígio na cultura, que servem de modelo de comportamento para seus membros. Os rituais consistem de atividades coletivas, supérfluas do ponto de vista técnico, mas socialmente indispensáveis. Os símbolos, heróis e rituais constituem as "práticas" da organização, e seu significado cultural está associado ao modo pelo qual são percebidos por todos que dela fazem parte. O núcleo da cultura é formado por valores, que se referem a sentimentos raramente discutíveis, quase sempre inconscientes, e, por isso mesmo, não diretamente observáveis, mas revelados através de compor- 
tamentos alternativos (corresponderiam aos pressupostos básicos de Schein).

Fundamentando-se em tais concepções, os autores (Hofstede et al., 1990) desenvolveram um questionário destinado a identificar os valores e práticas (símbolos, heróis e rituais) que caracterizam a cultura organizacional, sendo que a análise fatorial do instrumento evidenciou que ele se diferenciava em três dimensões subjacentes aos valores (necessidade de segurança, centralidade do trabalho e necessidade de autoridade) e seis dimensões subjacentes às práticas (orientação para processos $\mathrm{X}$ para resultados; orientação para funcionários X para a função; paroquial X profissional; sistema aberto $\mathrm{X}$ fechado; controle brando $\mathrm{X}$ rígido e normativo $\mathrm{X}$ pragmático). Estudos posteriores realizados com o questionário levaram Hofstede e colaboradores (1990) a concluir que os valores indubitavelmente moldam a cultura, porém é através das práticas que ela afeta os membros da organização, razão pela qual as percepções compartilhadas das práticas diárias constituem a essência da cultura organizacional.

Calori e Sarnin (1991) apresentam um modelo integrado de cultura corporativa que, de certa forma, representa uma síntese dos modelos anteriores. Partindo do centro para a periferia, postulam que a cultura de uma organização emerge através de pressupostos básicos, valores, normas de comportamento e de suas manifestações mais visíveis e diretas, tais como os símbolos (linguagem, rituais, mitos, arquitetura, etc.) e as práticas gerenciais (sistemas de recrutamento e seleção, sistemas de avaliação e recompensa, relações com clientes, competidores e com o ambiente social, etc.). Os autores, entretanto, elaboraram um questionário para avaliação da cultura organizacional voltado apenas para os valores e práticas, tendo verificado que os valores agregaram-se em doze dimensões e as práticas, em dezessete dimensões.

A análise de alguns dos principais instrumentos desenvolvidos para a avaliação das manifestações da cultura organizacional revela, portanto, que eles enfatizam prioritariamente os traços culturais associados a valores, normas comportamentais e práticas organizacionais, e vêm sendo adotados freqüentemente nos estudos destinados a elucidar o impacto que a cultura das organizações exerce nas atitudes e comportamentos expressos pelos indivíduos que as integram.

No Brasil, contudo, os estudos sobre cultura organizacional ainda são esparsos, quando comparados ao grande número de investigações estrangeiras desenvolvidas nas décadas de 80 e 90. De todo modo, é possível constatar um crescente interesse dos pesquisadores nacionais (Freitas, 1991; Gomide Jr, 1999; Tamayo, 1998a; Thiollent, 1997; Tomei \& Braustein, 1994) pela análise das implicações da cultura para os diferentes aspectos da vida organizacional. Atendose especificamente aos instrumentos originalmente brasileiros ou adaptados com a finalidade de apreender a cultura da organização, também fica patente o reduzido número de investigações desenvolvidas com esse objetivo até o presente momento.

No que diz respeito aos instrumentos adaptados, Oliveira, Gomide Jr., Martins, Marques e Cunha (1999) realizaram recentemente uma adaptação do OCI para amostras brasileiras, na qual encontraram apenas em parte os resultados originalmente obtidos, já que os 120 itens do instrumento, de modo contrário ao observado na versão norte-americana, que se apresenta configurada em doze dimensões, agruparam-se em apenas seis fatores consistentes (afiliação, competição, dependência, aprovação, realização e humanismoencorajamento).

$\mathrm{Na}$ categoria de instrumentos genuinamente brasileiros voltados para a avaliação da cultura organizacional só foram encontradas referências às escalas de Gomide Jr. e Martins (1997) e de Tamayo e Gondim (1996). Tomando por base a tipologia de Handy (1994), que propõe quatro tipos de cultura - cultura do clube (caracterizada pela centralização do poder na mão de uma única pessoa); cultura da função (marcada pela adoção prioritária de procedimentos extremamente burocráticos), cultura da tarefa (preocupada com a valorização da competência como forma de ascensão ao poder) e cultura existencial (preocupada com a autonomia e liberdade individuais) -, Gomide Jr. e Martins (1997) desenvolveram quatro escalas, associadas respectivamente aos quatro diferentes tipos de cultura, tendo-as validado através de técnicas de análise fatorial e obtido bons índices de consistência interna em todas elas.

Já Tamayo e Gondim (1996), na tentativa de verificar a estrutura dos valores das organizações, no que se refere a seus interesses básicos, construíram uma escala que, em sua forma final, compôs-se de 38 valores distribuídos em cinco fatores ou dimensões, relacionados à eficácia e eficiência visando a qualidade do produto, interação no trabalho, gestão hierárquica tradicional, inovação e respeito ao servidor, os quais apresentaram coeficientes de consistência interna bastante satisfatórios.

O exame das escalas nacionais revela que as de Gomide Jr. e Martins (1997) não se destinam diretamente à avaliação de elementos culturais presentes na organização, mas sim à identificação de padrões ou estilos de administração que a caracterizam, muito embora tais estilos encontrem-se permeados por certos valores e se concretizem em determinadas práticas. Já a escala de Tamayo e Gondim (1996), ao invés de conter conjuntos de frases, nas quais determinados valores encontram-se subentendidos, conforme procedimento adotado por Hofstede e colaboradores (1990), por exemplo, apóia-se na avaliação direta de um conjunto de valores, que se fazem acompanhar apenas de uma definição sucinta, o que limita as possibilidades de mensuração do grau em que cada um deles contribui para a configuração da cultura da organização. Cumpre ressaltar, ainda, que nenhum dos dois instrumentos objetivou avaliar diretamente as práticas organizacionais, que têm sido concebidas como o cerne da cultura por alguns autores (Calori \& Sarnin, 1991; Hofstede et al., 1990).

Justificam-se, assim, estudos adicionais voltados para a construção de instrumentos brasileiros de avaliação da cultura organizacional, que possam preencher as lacunas anteriormente apontadas. Nesse sentido, o presente trabalho pre- 
tendeu desenvolver e realizar uma análise preliminar das características psicométricas de uma escala de avaliação da cultura das organizações, através dos valores e práticas que a tipificam.

\section{Método}

\section{Elaboração da escala}

Para se realizar um mapeamento inicial dos valores e práticas organizacionais comumente adotados em empresas sediadas na cidade do Rio de Janeiro, que pudesse fornecer subsídios à elaboração da escala, foi desenvolvido um roteiro de entrevista semi-estruturado que, apoiado nos modelos de Calori e Sarnin (1991) e de Hofstede e colaboradores (1990), indagava sobre as metas prioritárias da organização e as atividades, atitudes e formas de relacionamento enfatizadas ou consideradas mais importantes por ela, assim como sobre os procedimentos adotados para tomada de decisões, planejamento de mudanças, distribuição de recompensas, atendimento aos clientes internos e externos etc.

Tal roteiro foi aplicado em dois diferentes membros (diretores e/ou gerentes) de empresas públicas e privadas, de médio e grande porte, pertencentes aos ramos de comércio, ensino e prestação de serviços, perfazendo um total de 9 empresas e 17 entrevistados, já que em uma das organizações foi possível contar apenas com um diretor.

As entrevistas foram gravadas, transcritas e submetidas à análise de conteúdo, daí emergindo várias dimensões associadas a valores e práticas organizacionais, bem como uma série de afirmativas relacionadas a cada uma dessas dimensões. Tais afirmativas deram origem à versão inicial do questionário, que ficou composta por 126 itens dispostos de forma aleatória, dos quais 68 associavam-se a valores e 58, a práticas organizacionais.

\section{Amostra}

A versão inicial do instrumento foi administrada a 823 membros de empresas situadas na cidade do Rio de Janeiro, cujas características eram similares às das organizações contatadas por ocasião da realização das entrevistas. Desse total, $55 \%$ pertenciam ao sexo masculino e $41 \%$ ao sexo feminino ( $4 \%$ da amostra não prestaram essa informação). A idade média foi de 35,83 anos (D.P.=9,47), o tempo médio de serviço foi igual a 6,13 anos (D.P. $=6,67$ ) e a grande maioria apresentava nível universitário (44\%) ou havia completado o ensino médio (34\%).

\section{Procedimento}

A aplicação dos questionários ocorreu de forma individual ou coletiva, nas próprias empresas, após a obtenção de autorização de seus responsáveis e de concordância de seus membros em colaborarem com a pesquisa. Os sujeitos foram solicitados a indicar o grau em que cada uma das afirmativas se aplicava efetivamente a sua organização, em escalas de formato Likert de 5 pontos, variando de "não se aplica de modo nenhum à minha empresa" (1) a "aplica-se totalmente à minha empresa" (5).

\section{Análise dos dados}

Adotando-se os procedimentos de análise fatorial exploratória recomendados por Gorsuch (1983), Kline (1994) e Pedhazur e Schmelkin (1991), as matrizes de intercorrelações correspondentes aos valores e às práticas foram separadamente submetidas a análise dos componentes principais. Em seguida, tomando-se por base os resultados da distribuição de valores críticos, tais matrizes foram analisadas fatorialmente através do método dos eixos principais (principal axis factoring), com rotação ortogonal e oblíqua. O coeficiente Alfa de Cronbach foi utilizado para o cálculo do índice de precisão ou consistência interna de cada fator.

\section{Resultados}

A análise dos componentes principais dos 68 itens correspondentes aos valores extraiu quatorze fatores com valores críticos (Eigenvalues) acima de 1, os quais foram responsáveis por $55 \%$ da variância total do instrumento. Contudo, a distribuição de valores críticos (scree test) revelou que o número ideal de fatores a serem extraídos situava-se entre dois e quatro.

Nesse sentido, foram realizadas, em seguida, análises fatoriais dos eixos principais com soluções antecipadas de dois a quatro fatores, através dos métodos de rotação ortogonal (Varimax) e oblíqua (Oblimin). Considerando-se, entretanto, que alguns dos fatores apresentaram-se consideravelmente correlacionados, optou-se pelo método de rotação oblíqua e pela solução de quatro fatores, por ter sido a que forneceu a melhor representação da estrutura interna da escala. Tais fatores foram responsáveis por $34 \%$ da variância total do conjunto de itens relacionados a valores e neles foram retidos os itens que apresentaram cargas fatoriais iguais ou superiores a 0,30 e congruência conceitual com os demais itens do fator.

O Fator 1 obteve valor crítico de 15,99 e foi responsável por $24 \%$ da variância total. O conteúdo de seus 23 itens associa-se à valorização dos empregados que executam suas tarefas com eficácia e competência, demonstrando espírito de colaboração, habilidade, dedicação, profissionalismo e capacidade de iniciativa, contribuindo, desse modo, para o alcance das metas comuns da organização. Nesse sentido, tal fator foi denominado de "Profissionalismo cooperativo" (Tabela 1).

O Fator 2 foi rotulado de "Rigidez na estrutura hierárquica de poder", por ter concentrado itens referentes a valores presentes em organizações definidas por um sistema de autoridade centralizado e autoritário que dificulta o crescimento profissional e o reconhecimento do elemento humano. Tal fator ficou com 13 itens responsáveis por 5\% da variância total, tendo obtido valor crítico igual a 3,52 (Tabela 2).

Os oito itens que compuseram o Fator 3 denotam a valorização prioritária da competência, do desempenho e eficácia individuais na execução de tarefas para a obtenção dos objetivos desejados, ainda que isso implique a necessidade de "passar por cima" dos colegas que almejam objetivos semelhantes. Sendo assim, tal fator foi chamado de "Profissionalismo competitivo e individualista", tendo apresentado valor crítico igual a 2,06 e explicado 3\% da variância total (Tabela 3). 
Tabela 1.

Cargas fatoriais e comunalidades da dimensão "Profissionalismo cooperativo"

\begin{tabular}{|c|c|c|}
\hline Itens & $\begin{array}{l}\text { Cargas } \\
\text { fatoriais }\end{array}$ & $\begin{array}{l}\text { Comunalid } \\
\text { ades (h2) }\end{array}$ \\
\hline 1. A cooperação é mais valorizada que a competição & 0,40 & 0,23 \\
\hline $\begin{array}{l}\text { 11. As idéias criativas dos empregados são usadas para a obtenção de melhores } \\
\text { resultados com menos recursos }\end{array}$ & 0,33 & 0,29 \\
\hline 14. As iniciativas individuais dos empregados são estimuladas & 0,40 & 0,45 \\
\hline $\begin{array}{l}\text { 19. As iniciativas dos empregados são valorizadas quando não contrariam os } \\
\text { interesses da empresa }\end{array}$ & 0,34 & 0,18 \\
\hline 22. A competição dentro das regras de boa convivência é sempre estimulada & 0,37 & 0,33 \\
\hline 24. O espírito de colaboração é uma atitude considerada muito importante & 0,62 & 0,38 \\
\hline $\begin{array}{l}\text { 51. O envolvimento com os ideais da empresa é uma atitude bastante } \\
\text { valorizada }\end{array}$ & 0,43 & 0,43 \\
\hline $\begin{array}{l}\text { 62. Os empregados que conseguem fazer carreira são os que se esforçam e } \\
\text { mostram vontade de aprender }\end{array}$ & 0,44 & 0,42 \\
\hline 63. A preocupação do empregado com a qualidade de seu serviço é bem vista & 0,64 & 0,47 \\
\hline 70. Ser cordial com os colegas é uma das atitudes mais estimuladas & 0,54 & 0,40 \\
\hline 75. O esforço e a dedicação ao trabalho são qualidades bastante apreciadas & 0,66 & 0,54 \\
\hline $\begin{array}{l}\text { 79. A capacidade de executar uma variedade de tarefas é extremamente } \\
\text { valorizada }\end{array}$ & 0,56 & 0,47 \\
\hline 80. O profissionalismo dos empregados é visto como uma grande virtude & 0,72 & 0,58 \\
\hline $\begin{array}{l}\text { 82. A ascensão profissional é uma decorrência natural do mérito e competê ncia } \\
\text { dos empregados }\end{array}$ & 0.40 & 0,44 \\
\hline $\begin{array}{l}\text { 84. A preocupação em superar as dificuldades do dia-a-dia é vista como de } \\
\text { grande valor }\end{array}$ & 0,68 & 0,55 \\
\hline $\begin{array}{l}\text { 87. Os empregados que fazem carreira rapidamente são os que "vestem a } \\
\text { camisa" da casa }\end{array}$ & 0,34 & 0,32 \\
\hline $\begin{array}{l}\text { 89. Os empregados que demonstram dedicação e espirito de colaboração } \\
\text { são os melhores modelos a screm scguidos }\end{array}$ & 0,67 & 0,50 \\
\hline $\begin{array}{l}\text { 91. As pessoas que fazem carreira rapidamente são as que demonstram maiores } \\
\text { conhecimentos dentro de suas áreas }\end{array}$ & 0,40 & 0,39 \\
\hline $\begin{array}{l}\text { 96. A qualidade do serviço executado é considerada uma das maiores virtudes } \\
\text { do empregado }\end{array}$ & 0,64 & 0,45 \\
\hline $\begin{array}{l}\text { 101. Os empregados que "vestem a camisa" são as figuras mais valorizadas } \\
\text { dentro da organização }\end{array}$ & 0,36 & 0,32 \\
\hline $\begin{array}{l}\text { 109. As iniciativas dos empregados são incentivadas, mas ficam sob o controle } \\
\text { de seus chefes imediatos }\end{array}$ & 0,41 & 0,24 \\
\hline $\begin{array}{l}\text { 110. Os diretores que inovam e promovem mudanças significativas são os } \\
\text { verdadeiros modelos a serem seguidos }\end{array}$ & 0,40 & 0,42 \\
\hline $\begin{array}{l}\text { 115. Os empregados que se comprometem com a missảo e os ideais da empresa } \\
\text { tomam-se modelos para os demais membros da organização }\end{array}$ & 0,44 & 0,49 \\
\hline
\end{tabular}

O quarto e último fator retirado do conjunto de itens concernentes aos valores foi intitulado de "Satisfação e bemestar dos empregados", por apresentar valores característicos de empresas que investem no bem-estar, satisfação e motivação dos empregados, procurando, assim, humanizar o local de trabalho e torná-lo agradável e prazeroso. Tal fator ficou composto por 11 itens, que explicaram $2 \%$ da variância, e teve valor crítico de 1,39 (Tabela 4).

Em síntese, a versão final do questionário para a avaliação da cultura organizacional, no que diz respeito aos valores, compôs-se de 55 itens distribuídos em 4 fatores. Os coeficientes Alfa de Cronbach revelaram, respectivamente, resultados iguais a 0,$93 ; 0,74 ; 0,74 ;$ e 0,89 , evidenciando, assim, que todos os fatores alcançaram bons índices de consistência interna.

A análise dos 58 itens correspondentes às práticas organizacionais extraiu doze fatores com valores críticos (Eigenvalues) acima de 1, os quais foram responsáveis por $52 \%$ da variância total do instrumento. A distribuição de valores críticos (scree test) apontou, porém, um número máximo de quatro fatores a serem extraídos. Assim, foram efetuadas, posteriormente, análises fatoriais dos eixos principais com soluções antecipadas de dois a quatro fatores, utilizando-se os métodos de rotação ortogonal (Varimax) e oblíqua (Oblimin). De modo semelhante ao verificado com o conjunto de itens associados aos valores, foi observado que os 
Tabela 2

Cargas fatoriais e comunalidades da dimensão "Rigidez na estrutura hierárquica de poder"

\begin{tabular}{lcc}
\multicolumn{1}{c}{ Itens } & $\begin{array}{c}\text { Cargas } \\
\text { fatoriais }\end{array}$ & $\begin{array}{c}\text { Comunali } \\
\text { dades }\left(\mathrm{h}^{2}\right)\end{array}$ \\
\hline $\begin{array}{l}\text { 20. O crescimento profissional não costuma ser recompensado } \\
\text { financeiramente }\end{array}$ & 0,54 & 0,28 \\
26. Não há figuras importantes que possam servir de exemplo & 0,37 & 0,15 \\
para os empregados & 0,30 & 0,17 \\
40. Manda quem pode, obedece quem tem juízo & 0,45 & 0,28 \\
43. A dificuldade de ascensão profissional leva a empresa a & & 0,27 \\
perder bons empregados para os concorrentes & 0,52 & 0,24 \\
60. A criatividade não é recompensada como deveria ser & 0,50 & 0,33 \\
65. Não há espaço para iniciativas individuais dos empregados & 0,58 & 0,11 \\
76. As oportunidades de ascensão funcional são limitadas pela & & \\
rígida estrutura da empresa & 0,34 & 0,12 \\
93. A falta de recursos financeiros impede a valorização do bem - \\
estar dos empregados
\end{tabular}

fatores eram correlacionados, o que indicou a adoção do método de rotação oblíqua, além da solução de quatro fatores, por ter sido a que forneceu a estrutura mais interpretável.

Os quatro fatores referidos explicaram $29 \%$ da variância total do conjunto de itens relacionados às práticas organizacionais, tendo-se retido, em cada um deles, os itens com cargas fatoriais iguais ou superiores a 0,30 , correlações item-total do fator acima de 0,20 e congruência conceitual com os demais itens do mesmo fator .

O Fator 1 obteve valor crítico de 11,27, foi responsável por $19 \%$ da variância total e ficou composto por 17 itens que se associam a práticas voltadas para o planejamento estraté- gico, tomada de decisões e atendimento ao cliente externo, com foco, portanto, nos escalões superiores da organização (Tabela 5). Os 14 itens que compõem o Fator 2 relacionam-se às práticas vinculadas aos clientes internos e aos sistemas de recompensas e treinamento adotados pela empresa, tendo tal fator sido responsável por $4 \%$ da variância total e obtido valor crítico igual a 2,40 (Tabela 6).

$\mathrm{O}$ exame dos itens que carregaram no Fator 3 apontou que tais itens apresentavam uma configuração estrutural de difícil interpretação do ponto de vista conceitual, apesar de ele ter apresentado valor crítico igual a 2,21 e explicado $4 \%$ da variância total. Este fator, além disso, foi o único que apre-

Tabela 3 .

Cargas fatoriais e comunalidades da dimensão "Profissionalismo competitivo e individualista".

\begin{tabular}{lcc}
\hline \multicolumn{1}{c}{ Itens } & $\begin{array}{c}\text { Cargas } \\
\text { fatoriais }\end{array}$ & $\begin{array}{c}\text { Comunalida } \\
\text { des }\left(\mathrm{h}^{2}\right)\end{array}$ \\
\hline $\begin{array}{l}\text { 5. A competição é estimulada como forma de crescimento pessoal e } \\
\text { de busca de poder }\end{array}$ & 0,35 & 0,26 \\
$\begin{array}{l}\text { 97. É necessário centralizar para manter a casa arrumada } \\
\text { 98. Somente os bons empregados recebem beneficios que lhes }\end{array}$ & 0,38 & 0,19 \\
$\begin{array}{l}\text { garantem um melhor bemrestar } \\
\text { 99. A criatividade é um dos requisitos básicos para a ocupação de }\end{array}$ & 0,45 & 0,29 \\
$\begin{array}{l}\text { cargos gerenciais } \\
\text { 102. O crescimento profissional é considerado indispensável à }\end{array}$ & 0,40 & 0,35 \\
$\begin{array}{l}\text { permanência do empregado na casa } \\
\text { 117. A competição é valorizada, mesmo que de forma nã } \quad \text { o sadia, } \\
\text { porque o objetivo maior da empresa é a produtividade e o lucro }\end{array}$ & 0,61 & 0,37 \\
123. Procura-se eliminar a pessoa mal vista & 0,36 & 0,38 \\
124. A competição é vista como indispensável à obtenção de bons & 0,60 & 0,20 \\
resultados & & 0,43 \\
\hline
\end{tabular}


Tabela 4.

Cargas fatoriais e comunalidades da dimensão "Satisfação e bem-estar dos empregados".

\begin{tabular}{|c|c|c|}
\hline Itens & $\begin{array}{l}\text { Cargas } \\
\text { fatoriais }\end{array}$ & $\begin{array}{l}\text { Comunali } \\
\text { dades }\left(h^{2}\right)\end{array}$ \\
\hline $\begin{array}{l}\text { 16. O bem-estar dos funcionários é visto como uma forma de garantir } \\
\text { maior produção }\end{array}$ & 0,46 & 0,48 \\
\hline $\begin{array}{l}\text { 25. As necessidades pessoais e o bem } \quad \text {-estar dos funcionários } \\
\text { constituem uma preocupação constante da empresa }\end{array}$ & 0,49 & 0,49 \\
\hline 31. Investe-se no crescimento profissional dos empregados & 0,63 & 0,44 \\
\hline $\begin{array}{l}\text { 46. Os empregados recebem treinamento para poderem desenvolver } \\
\text { sua criatividade }\end{array}$ & 0,52 & 0,30 \\
\hline $\begin{array}{l}\text { 55. Programas para aumentar a satisfação dos empregados são } \\
\text { regularmente desenvolvidos }\end{array}$ & 0,71 & 0,54 \\
\hline $\begin{array}{l}\text { 57. Procura -se manter uma atmosfera de segurança e estabilidade } \\
\text { para deixar os empregados satisfeitos e confiantes }\end{array}$ & 0,44 & 0,50 \\
\hline $\begin{array}{l}\text { 61. O crescimento dos empregados que são a "prata da casa" é } \\
\text { facilitado e estimulado }\end{array}$ & 0,40 & 0,35 \\
\hline $\begin{array}{l}\text { 73. Investe-se em um bom ambiente de trabalho com o objetivo de se } \\
\text { garantir o bem-estar dos funcionários }\end{array}$ & 0,40 & 0,50 \\
\hline $\begin{array}{l}\text { 77. Programas destinados a melhorar o bem-estar dos empregados são } \\
\text { implementados e testados }\end{array}$ & 0,66 & 0,50 \\
\hline $\begin{array}{l}\text { 100. As idé ias criativas dos empregados são postas em prática como } \\
\text { forma de torná-los mais motivados }\end{array}$ & 0,47 & 0,46 \\
\hline $\begin{array}{l}\text { 120. Metas pessoais, quando de grande valor, são incorporadas às } \\
\text { metas organizacionais }\end{array}$ & 0,40 & 0,41 \\
\hline
\end{tabular}

sentou um baixo índice de consistência interna $(\alpha=0,60)$, o que levou à decisão de retirá-lo da versão final do instrumento. Por fim, o quarto e último fator, com 8 itens, obteve valor crítico igual a 1,20 e explicou $2 \%$ da variância, tendo-se mostrado associado a práticas orientadas para a promoção das relações interpessoais e satisfação dos empregados, favorecendo, assim, a coesão interna (Tabela 7).

Em resumo, a versão final do conjunto de itens concernentes às práticas organizacionais ficou composta por 39 itens distribuídos em 3 fatores, denominados de "Práticas de integração externa", "Práticas de recompensa e treinamento" e "Práticas de promoção do relacionamento interpessoal", os quais obtiveram, respectivamente, coeficientes Alfa de Cronbach iguais a 0,$87 ; 0,82$ e 0,75 , numa evidência de que todos os três fatores apresentaram índices de consistência satisfatórios.

\section{Conclusões}

A forma final do questionário de cultura organizacional, composta de 94 itens distribuídos por quatro dimensões correspondentes a valores, e outras três associadas a práticas organizacionais, apresentou boas características psicométricas no que diz respeito a sua validade de construto, atestada através de procedimentos de análise fatorial exploratória. No que se refere à precisão, todos os fatores atenderam ao critério estabelecido por Nunnally (1978), de acordo com o qual pode-se considerar como satisfatório um coeficiente de precisão maior ou igual a 0,70 .
Em face de suas características psicométricas, assim como do escasso número de instrumentos brasileiros disponíveis para a avaliação da cultura organizacional, a referida escala poderá ser útil em pesquisas acadêmicas voltadas para a investigação do papel que a cultura desempenha na vida das organizações. Assim, por exemplo, seria interessante investigar o impacto dos valores e práticas endossados prioritariamente pela organização, segundo a percepção de seus membros, nas atitudes que estes membros demonstram em relação a ela, em seus comportamentos de trabalho e em sua eficiência e eficácia.

No que diz respeito às situações de diagnóstico, porém, a escala deve ser usada com cautela, na medida em que alguns de seus fatores apresentaram índices de consistência interna apenas satisfatórios. De todo modo, ela poderá ser adotada como instrumento auxiliar em situações nas quais a elaboração de um perfil a respeito da cultura organizacional possa oferecer subsídios ao planejamento estratégico de mudanças e à tomada de decisões.

Vale ressaltar, ainda, que os itens que compõem os quatro fatores concernentes aos valores foram desenvolvidos exclusivamente a partir de critérios empíricos, isto é, tomando-se por base as vivências e percepções dos indivíduos que participaram do estudo piloto. Ainda assim, seu conteúdo apresentou várias semelhanças com os fatores obtidos no estudo de Tamayo e Gondim (1996), também desenvolvido com amostras brasileiras. Assim é que os fatores de eficácia e eficiência, interação no trabalho, gestão e respeito aos servidores, observados por aqueles autores, mostraram-se 
Tabela 5 .

Cargas fatoriais e comunalidades da dimensão de "Práticas de integração externa".

\begin{tabular}{|c|c|c|}
\hline Itens & $\begin{array}{l}\text { Cargas } \\
\text { fatoriais }\end{array}$ & $\begin{array}{l}\text { Comu- } \\
\text { nalida- } \\
\text { des }\left(\mathrm{h}^{2}\right)\end{array}$ \\
\hline 6. A superação de metas pré-estabelecidas é uma preocupação constante & 0,42 & 0,32 \\
\hline 13. Os empregados têm uma noção clara dos principais objetivos da empresa & 0,37 & 0,31 \\
\hline 18. $\mathrm{O}$ atendimento às necessidades do cliente é uma das metas mais importantes & 0,64 & 0,45 \\
\hline 21. As decisões mais importantes são tomadas através de consenso da diretoria & 0,47 & 0,21 \\
\hline 29. Persegue-se a excelência de produtos e serviços como forma de satisfazer aos clientes & 0,66 & 0,48 \\
\hline $\begin{array}{l}\text { 32. O acompanhamento e atendimento das necessidades dos clientes é feito } \\
\text { constantemente }\end{array}$ & 0,57 & 0,48 \\
\hline $\begin{array}{l}\text { 33. Os gerentes (supervisores, chefes de departamento, etc.) têm autonomia apenas para } \\
\text { tomar decisões rotineiras relacionadas a suas áreas de atuação }\end{array}$ & 0,30 & 0,13 \\
\hline $\begin{array}{l}\text { 34. Os novos produtos e/ou serviços são testados conjuntamente pela empresa e seus } \\
\text { clientes }\end{array}$ & 0,34 & 0,32 \\
\hline 35. A comunicação das decisões obedece à hierarquia existente na empresa & 0,47 & 0,20 \\
\hline 36. As decisões surgem principalmente a partir da análise das necessidades do cliente & 0,53 & 0,38 \\
\hline 39. Mantêm-se relações amigáveis com os clientes & 0,60 & 0,38 \\
\hline $\begin{array}{l}\text { 42. As decisões têm como principal objetivo o aumento da capacidade competitiva da } \\
\text { empresa no mercado }\end{array}$ & 0,54 & 0,42 \\
\hline 54. As mudanças são planejadas para terem efeito a curto prazo & 0,35 & 0,23 \\
\hline 59. O retorno sobre os investimentos é uma preocupação permanente & 0,44 & 0,35 \\
\hline 64. As mudanças obedecem a um planejamento estratégico & 0,39 & 0,38 \\
\hline $\begin{array}{l}\text { 66. Os gerentes (supervisores, chefes de departamento, etc.) têm autonomia para tomar } \\
\text { decisões importantes relacionadas a suas áreas de atuação }\end{array}$ & 0,32 & 0,23 \\
\hline 71. As inovações são em geral introduzidas para atender às necessidades do mercado & 0,61 & 0,46 \\
\hline
\end{tabular}

Tabela 6.

Cargas fatoriais e comunalidades da dimensão de "Práticas de recompensa e treinamento".

\begin{tabular}{|c|c|c|}
\hline Itens & $\begin{array}{l}\text { Cargas } \\
\text { fatoriais }\end{array}$ & $\begin{array}{l}\text { Comunali } \\
\text { dades }\left(h^{2}\right)\end{array}$ \\
\hline 3. A dedicação dos empregados é recompensada & 0,33 & 0,45 \\
\hline $\begin{array}{l}\text { 27. As recompensas costumam ser dadas a grupos ou equipes de } \\
\text { trabalho que se destacam e não individualmente }\end{array}$ & 0,42 & 0,22 \\
\hline $\begin{array}{l}\text { 30. Os empregados que apresentam idéias inovadoras costumam ser } \\
\text { premiados }\end{array}$ & 0,64 & 0,44 \\
\hline $\begin{array}{l}\text { 48. Os empregados sã o premiados quando apresentam um } \\
\text { desempenho que se destaca dos demais }\end{array}$ & 0,71 & 0,53 \\
\hline $\begin{array}{l}\text { 49. As promoçỏes costumam ser lineares e negociadas com os } \\
\text { sindicatos }\end{array}$ & 0,37 & 0,21 \\
\hline 53. As inovações costumam ser introduzidas através de treinamento & 0,47 & 0,32 \\
\hline $\begin{array}{l}\text { 72. Eventos sociais com distribuição de brindes são comumente } \\
\text { realizados para os empregados }\end{array}$ & 0,67 & 0,44 \\
\hline $\begin{array}{l}\text { 78. O aniversário da empresa costuma ser comemorado em } \\
\text { conjunto com todos os seus empregados }\end{array}$ & 0,33 & 0,23 \\
\hline $\begin{array}{l}\text { 81. Os familiares dos empregados costumam também participar dos } \\
\text { eventos e festas }\end{array}$ & 0,35 & 0,22 \\
\hline 86. As promoções são definidas por avaliação de desempenho & 0,49 & 0,34 \\
\hline $\begin{array}{l}\text { 104. Os empregados com desempenho permanentemente baixo são } \\
\text { demitidos }\end{array}$ & 0,36 & 0,19 \\
\hline $\begin{array}{l}\text { 105. As inovações costumam ser introduzidas através de programas } \\
\text { de qualidade }\end{array}$ & 0,57 & 0,46 \\
\hline $\begin{array}{l}\text { 113. Os empregados costumam ser premiados quando alcançam } \\
\text { metas pré-estahelecidas }\end{array}$ & 0,69 & 0,52 \\
\hline $\begin{array}{l}\text { 116. Existem normas que estabelecem o grau de participação dos } \\
\text { empregados no processo de tomada de decisões }\end{array}$ & 0,44 & 0,22 \\
\hline
\end{tabular}


Tabela 7.

Cargas fatoriais e comunalidades da dimensão de "Práticas de relacionamento interpessoal".

\begin{tabular}{|c|c|c|}
\hline Itens & $\begin{array}{l}\text { Cargas } \\
\text { fatoriais }\end{array}$ & $\begin{array}{l}\text { Comunali } \\
\text { dades }\left(h^{2}\right)\end{array}$ \\
\hline $\begin{array}{l}\text { 2. Os empregados têm ampla liberdade de acesso aos } \\
\text { diretores }\end{array}$ & 0,43 & 0,35 \\
\hline $\begin{array}{l}\text { 37. Investe-se na satisfação dos funcionários para que eles } \\
\text { prestem um bom atendimento aos clientes }\end{array}$ & 0,34 & 0,52 \\
\hline $\begin{array}{l}\text { 41. Prevalece um grande espí rito de união entre os } \\
\text { empregados }\end{array}$ & 0,35 & 0,27 \\
\hline $\begin{array}{l}\text { 45. Os chefes imediatos são como pais para os } \\
\text { empregados }\end{array}$ & 0,52 & 0,35 \\
\hline $\begin{array}{l}\text { 47. As necessidades pessoais dos empregados são } \\
\text { analisadas caso a caso, não havendo programas ou } \\
\text { políticas gerais para esse atendimento }\end{array}$ & 0,35 & 0,24 \\
\hline $\begin{array}{l}\text { 58. É prática comum a comemoração dos aniversários } \\
\text { pelos empregados }\end{array}$ & 0,37 & 0,16 \\
\hline $\begin{array}{l}\text { 83. As relações entre empregados e membros do alto } \\
\text { escalão são cordiais e amigáveis }\end{array}$ & 0,42 & 0,44 \\
\hline $\begin{array}{l}\text { 108. Os empregados se relacionam como se fossem uma } \\
\text { grande família }\end{array}$ & 0,49 & 0,36 \\
\hline
\end{tabular}

conceitualmente similares, respectivamente, aos fatores de profissionalismo cooperativo, profissionalismo competitivo, rigidez na estrutura hierárquica de poder e bem-estar dos funcionários presentemente obtidos.

Por outro lado, tanto as dimensões de valores quanto as dimensões de práticas que compõem a atual escala apresentaram divergências consideráveis com os fatores derivados por Hofstede e colaboradores (1990), em organizações holandesas e dinamarquesas, assim como com os fatores observados por Calori e Sarnin (1991), em empresas francesas, o que permite a suposição de que os valores e práticas que configuram a organização sofrem influências da cultura nacional e evidencia a necessidade de investigações futuras que possam esclarecer tal relação.

Em síntese, a escala em questão, ao possibilitar a avaliação do modo pelo qual as empresas imprimem sua "marca", isto é, do grau em que certos traços ou elementos culturais a simbolizam e representam, constitui um instrumento valioso para as investigações voltadas para a análise e compreensão da intricada e complexa rede de fenômenos relacionais e estruturais responsáveis pelo adequado funcionamento das organizações.

\section{Referências}

Calori, R., \& Sarnin, P. (1991). Corporate culture and economic performance: A French study. Organization Studies, 12(1), 49-74.

Cooke, R. A., \& Lafferty, J. C. (1984). Level V Organizational Culture Inventory. Plymouth: Human Synergistics.

Cooke, R. A., \& Lafferty, J. C. (1989). Organizational Culture Inventory. Plymouth: Human Synergistics.

Cooke, R. A., \& Rousseau, D. M. (1988). Behavioral norms and expectations: A quantitative approach to the assessment of organizational culture. Group and Organization Studies, 13(3), 245-273.
Cooke, R. A., \& Szumal, J. L. (1993). Measuring normative beliefs and shared behavioral expectations in organizations: The reliability and validity of the Organizational Culture Inventory. Psychological Reports, 72(3), 12991330 .

Freitas, M. E. (1991). Cultura organizacional: formação, tipologia e impacto. São Paulo: Makron.

Gomide Jr., S. (1999). Antecedentes e conseqüentes das percepções de justiça no trabalho. Tese de doutorado não-publicada. Universidade de Brasília, Brasília.

Gomide Jr., S., \& Martins, M. C. F. (1997). Os deuses da administração: construção e validação de quatro escalas para medida de cultura organizacional. Psicologia: Teoria e Pesquisa, 13(3), 311-316.

Gorsuch, R. L. (1983). Factor analysis (2 $2^{\underline{a}}$ ed.). Hillsdale: Erlbaum.

Handy, C. (1994). Deuses da administração. (2 ${ }^{\underline{a}}$ ed). São Paulo: Saraiva/SENAC.

Kline, P. (1994). An easy guide to factor analysis. London: Routledge.

Hofstede, G., Neuijen, B., Ohayv, D. D., \& Sanders, G. (1990). Measuring organizational cultures: A qualitative and quantitative study across twenty cases. Administrative Science Quarterly, 35(2), 286-316.

Nunnally, J. C. (1978). Psychometric theory (2 ${ }^{\underline{a}}$ ed.). New York: McGraw-Hill.

Oliveira, A. F., Gomide Jr., S., Martins, M. C. F., Marques, M. N., \& Cunha, W. B. (1999). Cultura organizacional: adaptação e validação de um instrumento de medida para o Brasil [Resumo]. In Sociedade Brasileira de Psicologia (Org.), XXIX Reunião Anual de Psicologia. Resumos (p. 215). Ribeirão Preto: Autor.

Pedhazur, E. J., \& Schmelkin, L. P. (1991). Measurement, design and analysis: An integrated approach. Hillsdale: Erlbaum.

Pettigrew, A. M. (1979). On studying organizacional cultures. Administrative Science Quarterly, 24(4), 570-581.

Rousseau, D. M. (1990). Assessing organizational culture: The case for multiple methods. In B. Schneider (Org.), Organizational climate and culture (pp. 153- 192). San Francisco: Jossey-Bass.

Schein, E. H. (1991). What is culture. In P. J. Frost, L. F. Moore, M. R. Louis, C. C. Lundberg \& J. Martin (Orgs.), Reframing organizational culture (pp. 243-253). Newbury Park: Sage.

Schein, E. H. (1992). Organizational culture and leadership (2 ed.). San Francisco: Jossey-Bass. 
Smircich, L. (1983). Concepts of culture and organizational analysis. Administrative Science Quarterly, 28(3), 339-358.

Tamayo, A. (1998a). Valores organizacionais: sua relação com satisfação no trabalho, cidadania organizacional e comprometimento afetivo. Revista de Administração, 33(3), 56-63
Tamayo, A., \& Gondim, M. G. C. (1996). Escala de valores organizacionais. Revista de Adminstração, 31(2), 62-72.

Thiollent, M. (1997). Pesquisa-ação nas organizações. São Paulo: Atlas.

Tomei, P. A., \& Braunstein, M. L. (1994). Cultura organizacional e privatização: a dimensão humana. São Paulo: Makron.

Nota

1 Trabalho anteriormente apresentado na XXX Reunião Anual de Psicologia, realizada na Universidade de Brasília, de 26 a 29 de outubro de 2000.

Maria Cristina Ferreira, doutora em Psicologia pela Fundação Getúlio Vargas (RJ), é professora da Universidade Gama Filho, RJ.

Eveline Maria Leal Assmar, doutora em Psicologia pela Universidade Federal do Rio de Janeiro (RJ), é professora da Universidade Gama Filho, RJ.

Katia Maria Felipe Estol, mestre em Psicologia pela Universidade Gama Filho, RJ, é consultora organizacional. Maria Cristina da Costa Chagas Helena, mestre em Psicologia pela Universidade Gama Filho, RJ, é professora do Centro Universitário Celso Lisboa, RJ.

Maria do Carmo Figueiredo Cisne, mestre em Psicologia pela Universidade Gama Filho, RJ, é professora da Universidade Estácio de Sá, RJ.

Endereço para correspondência:

[MCF] Rua Marquês de Valença, 80 apto. 602, 20550-030, Rio de Janeiro, RJ. E-mail: mcris @ centroin.com.br. Tel: (21)2569-1176. Fax: (21)2565-7903. 